\title{
Promotion of innovative medical institutions in the era of globalization and economic knowledge
}

\author{
Natalia Pashkus ${ }^{1,}$, Nadegda Starobinskaya ${ }^{1}$, and Petr Shvetc ${ }^{2}$ \\ ${ }^{1}$ Herzen State Pedagogical University, the Moika river emb., 48.St. Petersburg, Russia \\ ${ }^{2}$ St. Petersburg State University, Universitetskaya nab., 7-9, St. Petersburg, Russia
}

\begin{abstract}
In the context of globalization and economic knowledge, the sector of innovative medical services is becoming one of the determining factors in ensuring the high innovative potential of the country, ensuring the health and high quality of life of the population and creating conditions for a powerful spurt of economic growth. Therefore, the purpose of this article is to identify mechanisms for the effective development of regional medical clusters. Countries that are able to provide innovative medical services at a high level have global appeal. At the same time, innovative medical institutions, possessing unique technologies and knowledge in the field of treatment and provision of medical services, do not always have experience and knowledge in the field of promotion, especially in the global market. The proposed analysis tool will allow identifying characteristic intervals for institutions of different types of changes in the important characteristics of their innovative potential and assess their position in the global market for medical services. The application of this procedure will allow to assess the level of competitiveness of innovative medical institutions in the global knowledge economy and highlight for them effective tools for strategic development.
\end{abstract}

\section{Introduction}

In the era of globalization and the knowledge economy modern economic policy of Russia is aimed at supporting innovative growth of the economy, which can be implemented, among other things, by stimulating the development of high-tech clusters. [1,2] import substitution Policy requires active actions of the state (including for security reasons) in critical industries, which requires a well-thought-out policy in critical areas and taking into account the effects of the digital economy. $[3,4]$ in the knowledge economy, achieving global competitiveness requires a proper public policy and focus on innovative development. [5, 6] one of the perspective directions of creation and development of such clusters is the sphere of health care. The level of development of medicine in the region and the characteristics of the provision of medical services determine, among other things, the quality of life of the population of the region. Therefore, it is not surprising the popularity of projects to create a medical cluster in the region, which would improve the quality of life and launch the mechanism of innovative development. [7-9] Insufficient solvency of the country's medical

\footnotetext{
*Corresponding author nat_pashkus@mail.ru
} 
complex leads to low availability of medical services for its average resident and, in fact, undermines the competitiveness of the territory. The unavailability of medical services in this case is associated with both high direct costs for the purchase of services and indirect costs associated with obtaining it in another region (country), as well as with finding and obtaining access to information on the distribution of services.

It should be noted that even if there is a developed medical cluster in the region, the consumer's choice is complicated by the information asymmetry operating in this market. The consumer does not have enough confidence in the classic advertising channels used by medical institutions. More often, the consumer is guided by the opinion of their friends and acquaintances who have experience in obtaining medical services in the analyzed medical organization. This leads to a boom in viral marketing in the field of medicine, especially the predominant activity of medical organizations in social networks. Moreover, the consumer is not able to assess the real quality of medical services on his own, which makes him focus on visible differences and subjective assessments.

\section{Methodology: Breakthrough positioning strategy for medical institutions}

Medical institutions operate in a highly competitive environment, using typical types of marketing communications to promote their services. A prerequisite for the communication representation of a medical institution is the availability of a quality website of the organization with full information about the types, price and characteristics of medical services. Information about the possibility of obtaining a free medical service will also be valuable for the consumer, even if due to the convenience or speed of obtaining the service, the consumer prefers its paid option. In the presence of a high-quality website organization, in the eyes of the consumer, is the first test for compliance. Next, the consumer begins to study the information provided about the organization in social networks, focusing on identifying negative feedback and negative reactions. Mitigate negative information can only personal reviews of persons whom a person can strictly trust.

In the case of searching for information about the possibilities of treatment of certain diseases or diagnosis of the condition, even in regions with a developed medical cluster, the consumer either finds too much similar information that can not be effectively ranked, or simply does not know how to make a request to get the information he needs. As a result, medical institutions providing quality services with a relatively high cost are unfairly neglected in favor of institutions providing less quality, but cheaper and more widely covered in information sources services. However, "passing" a lot of medical institutions that provide standard medical services, the patient still then comes to those institutions that can really help him, though their services are objectively more expensive, but at the same time spends significant amounts to obtain standard services, collect information about treatment options and neutralize the consequences of improper or ineffective treatment.

Therefore, in the realities of the knowledge economy, reducing the level of information asymmetry in the market of medical services will not only increase the chances of a medical institution to succeed in competition, but also facilitate consumer choice, reduce its additional costs and reduce the possibility of negative or even dangerous consequences of improper treatment for health and life. The formation of such an information field accompanying the work of the medical cluster of the region, which would reduce the information asymmetry, requires the use of modern tools of strategic management in this sector. [10,11] one of these tools is a breakthrough positioning strategy, which is successfully used in various fields of activity. This strategic tool can be used in the promotion of medical institutions and their services, justification for the consumer to choose innovative types of services may be somewhat more expensive, but more effective and less dangerous for the patient. 
The breakthrough positioning strategy is based on the positioning of economic objects and products in the space of technology/innovation and style/design (see Fig. 1). This idea was first proposed by Jonathan Cagan and Craig Vogel [12], who developed a map of breakthrough positioning and identified the main factors contributing to the possibility of a market breakthrough. This tool has been developed and modified by the authors, which made it possible to apply it to various types of markets, as well as to assess the potentially attractive dominant positioning, with which you can implement a market breakthrough.

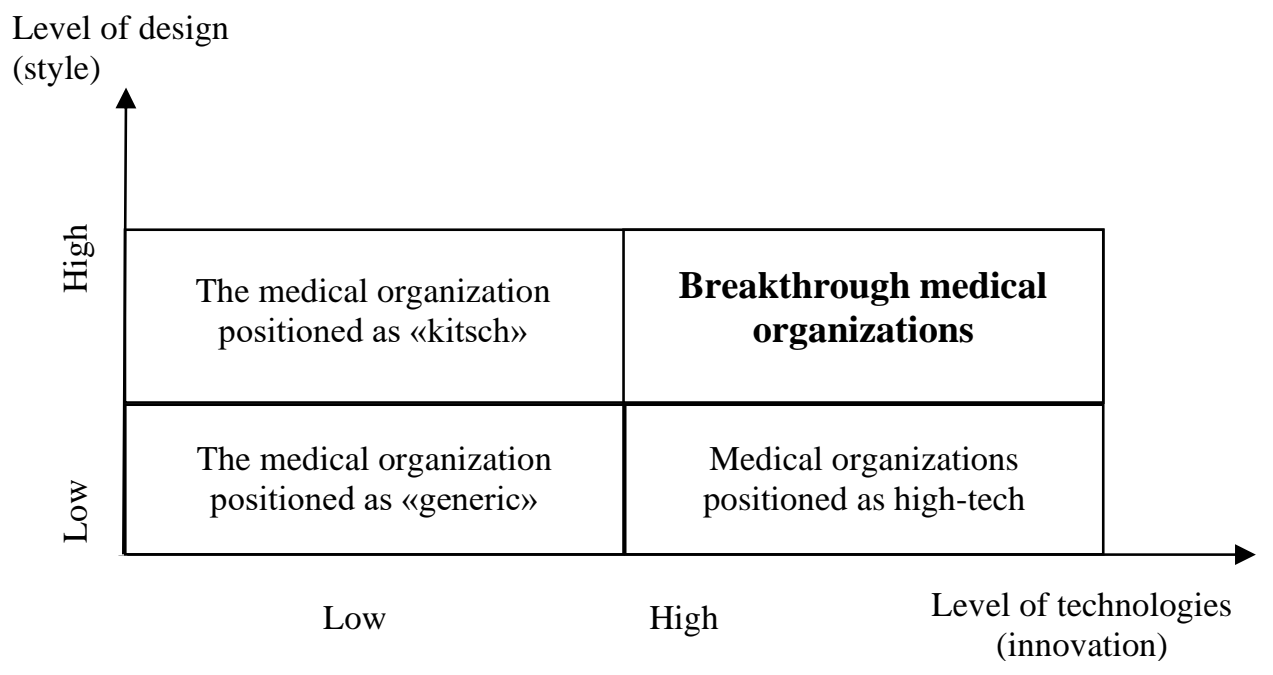

Fig. 1. Modified map positioning Cagan and Vogel for medical organizations

According to the proposed tool, all medical organizations and all types of medical services offered by them (both paid and free) can be classified according to these four quadrants of the matrix. Depending on the correspondence of the organization or its medical services to one of the categories of the matrix, certain strategies for their market promotion can be selected, ensuring maximum success in its positioning cluster.

\section{Results}

\subsection{Features of positioning of companies-geneticists.}

Analysis of the strategic positions of the matrix shows that the category of "generics" includes standard medical services at relatively low prices provided by insufficiently wealthy organizations in the medical market, or standard affordable services included in the compulsory health insurance policy (CHI). Such medical organizations can gain some popularity in the market due to their individual advantages, coherence in the process of providing medical services, minimizing prices for the consumer by reducing their costs for their provision or simplifying access to a range of services included in the CHI. Such organizations and their medical services may be competitive, in steady demand, and even have strong brands, but their evaluation by the consumer is in line with the desire to minimize costs. As a result, the consumer, first of all, will try to get these services for free, in the absence of such an opportunity will look for the cheapest treatment options.

Considering possibilities of the positioning of medical institutions of Saint-Petersburg, we can conclude that the majority of typical clinics, General hospitals, number of hospitals narrow focus and the majority of city drugstores are positioned in accordance with this cluster matrix. Such institutions mainly financed by public funds Ministry of health of Russia have 
on the balance sheet that meet the minimum requirements Arsenal (medical equipment, pharmaceutical products, etc.) and formatted according to the standard system of public medical institutions.

Among these institutions there are some more successful in the competitive relation, which stand out due to certain factors of competitive dominance. Most of them do not have a formed brand of the institution, offer a standard set of medical services, or consumers before applying to the organization, in principle, do not know what services this medical institution provides. The choice of the consumer in favor of a particular medical institution is carried out randomly (for example, in the provision of emergency medical care) or on the basis of the possibility of free access. Other things being equal, the consumer applies to the institution included in the compulsory health insurance policy, or the most geographically accessible.

If it is necessary to obtain paid medical services, the consumer of medical organizations of generics tries to get them at the lowest possible market prices, and does not consider it necessary to pay more even when receiving services of higher quality than expected. Moreover, even if generic health facilities provide reasonably good services, the consumer is more likely to pay directly to the doctor providing the higher-level medical service than to incur higher costs when receiving services from the organization. The consumer's belief that a doctor or other health care professional will perform better when making a certain contribution on the part of the patient, leads to the fact that some health care providers in principle do not want to provide free services. Comparison of the patient's costs in a private or public clinic may be quite comparable or even exceed all reasonable limits with the actual low quality of services and other unsatisfactory characteristics of the consumer services in a generic institution.

However, some private medical centers, despite the higher prices of paid medical services, also provide them poorly, focusing only on visible differences. As a result, the consumer is faced with the previously noted problem of information asymmetry, and can not make an objective choice. This once again convinces the consumer, ceteris paribus, to make a choice in favor of free or less expensive treatment.

Among the successful in this cluster of medical institutions in St. Petersburg can be called a Polyclinic complex on the Moscow 22, and in some areas of the city Children's hospital №1 or research Institute of emergency them. I. I. Janelidze. The activities of many medical institutions are quite heterogeneous. As a result, being successful generics in one treatment areas, in other areas, these medical organizations can be classified as high-tech or even breakthrough. Such promising areas of activity are present in the work of the Children's city hospital No. 1 , and in the activities of the Institute of emergency care. I. I. Janelidze. However, not always, carrying out positioning of medical directions in these categories, the applied strategies for medical institutions are successful.

As successful generics, health facilities ensure priority choices, which gives them the best additional funding and opportunities to improve the treatment base. The problem is that for most health care providers, falling into the "generics" category is not about making a reasonable choice, but is due to circumstances and a lack of other options. Such institutions "go with the flow", and most often do not think at all about the strategy of their development, except that it will be required from them by the Supervisory organizations in the medical sector, in this case the strategy is formulated and implemented formally.

Generics occupy, first of all, a niche in the provision of medical services to the population under the $\mathrm{CHI}$ policy, but due to strictly limited funding, these institutions remain stable in their positions and rarely make a qualitative leap in their development. In such institutions there is no effective system of personnel remuneration, linking the bonus system and the employee's contribution to ensuring the quality of medical services of the institution, to the formation of its image and the development of important, from the point of view of ensuring the strategy of the organization, activities. Consequently, it is not profitable, and sometimes 
dangerous, for talented doctors and Junior medical staff to exercise excessive diligence outside of their immediate responsibilities, in terms of possible complaints. Moreover, such a system encourages staff to accept remuneration from patients, and sometimes extort this remuneration.

\subsection{Features positioning kitsch company.}

Medical organizations belonging to the second category of the matrix, namely the category of "kitsch", focus on the visible differences in the provision of medical services. In terms of its technological characteristics and the real quality of medical services organizations in this category do not differ from the services of generics. At the same time, medical organizations of kitsch create an attractive environment for the consumer to provide medical services and focus on the convenience of their provision. The patient does not have to wait long in line or demand to receive this service, the medical staff is extremely polite and helpful, the atmosphere of reception rooms, treatment rooms, wards, treatment rooms and operating rooms has the patient to relax, it is accompanied by soft soft music, distracting and soothing accessories. By their technological equipment, such medical organizations also clearly benefit in relation to medical organizations generics. But these differences swing, first of all, the novelty of the equipment, a more convenient form of providing research results, more automation and better electronic control system. Not always with the help of this equipment you can get qualitatively different results of research, and not always experts are able to fully use this more advanced equipment. The rate in the knowledge economy is on intangible assets of the organization, the specifics of consumer motivation and the fashion factor. [10,13] but the patient clearly has the impression of a higher technological quality of medical services.

This category includes many private medical clinics that provide medical services on a commercial basis. For example, prominent representatives of successful C \& $\mathrm{m}$ organizations are:

- Network of private clinics of a wide profile "Scandinavia»;

- Network of private dental clinics "Intan»;

- Network of clinics of laser cosmetology "Laser doctor".

These institutions tend to operate at the expense of private investors and are aimed at selling as many medical services as possible at inflated prices. Basically, differ from the category of medical organizations generics expanded Arsenal and variety of medical equipment, pharmacological products, medical supplies, etc., novelty and stylistic performance of medical equipment and materials used, as well as the conditions of patient care, characterized by increased comfort.

Medical organizations of kitsch have sufficient funding to maintain the stability of the implemented strategy. In such medical institutions there is a sufficiently high entrance qualification for hiring staff at all levels, but also higher incomes, allowing staff not to be interested in remuneration from patients. However, often the staff is forced to offer patients to buy quite expensive complementary medical services consumed goods, for example, expensive pharmacological products, use overpriced materials, medical devices and devices (eg, clamps, bandages, bandages, etc.). Moreover, the patient takes it for granted, as often these materials and tools, if not really more effective, at least more convenient to use. At the same time, for the transition to the category of "high-tech (innovative)" and, moreover, "Breakthrough" these medical institutions do not have enough really advanced methods of treatment, unique abilities based on exclusive knowledge and skills of the staff, as well as the idea of positioning and promotion in the market of medical services. 


\subsection{Features of positioning of high-tech companies.}

Currently, St. Petersburg can rightly be called the scientific capital of Russia. On its territory there are many research centers and institutions, including medical orientation, some of which are unique. As a rule, " high-tech (innovative)" medical institutions have a narrow focus, or are created to serve a certain special category of patients. As a rule, such institutions have a good level of funding from public and private funds.

This category includes scientific-medical and medical institutions, for example, the allRussian center of emergency and radiation medicine. A. M. Nikiforova EMERCOM of Russia. The institution provides a wide range of medical services. It was created at the expense of the EMERCOM Fund of Russia, as a specialized center for the rehabilitation of patients affected by emergencies. However, in the process of work, the institution failed to fully utilize the available medical Arsenal, so it was decided to start receiving ordinary patients on a budgetary and commercial basis, which in turn secured the center in the category of "high-tech (innovative)". It should be noted that access to a wide market of commercial medical services, just deprived this medical center of the opportunity to move into the category of"breakthrough".

Another example of a medical organization of this type is the fgbi research Institute of influenza of the Ministry of health of Russia. The institution provides medical services for the prevention and treatment of viral diseases, but the narrow focus and limited funding of the Institute does not allow it to move into the category of "Breakthrough" institutions. The main range of activities of the institution is associated exclusively with scientific research. The Institute develops new methods, develops and tests new medical equipment, creates innovative pharmacological drugs, some of which themselves become innovative or even breakthrough products.

Another example of medical organizations in this category is FSBMEE Military medical Academy. S. M. Kirov MO of Russia. The Academy provides a wide range of medical services to Russian servicemen at the expense of the state budget, as well as to civilians on a commercial basis. At the expense of a wide audience of patients, this institution is deprived of the opportunity to develop more focused any particular direction in the provision of medical services, which excludes the transition of the Academy into the category of "Breakthrough" medical organizations. However, the availability of various types of funding, the existence of an extensive scientific base and unique practical experience of specialists, allows this organization to consistently meet all the requirements of the category of high-tech (innovative) medical institutions.

Typically high-tech (innovative) medical institution is the Russian research Institute of Hematology and Transfusiology of Federal medical-biological Agency (fgbu Rosniigd FMBA Rossii), commonly known as blood Institute. The medical institution specializes, first of all, in highly specialized scientific researches, conducts active educational activity, develops new mechanisms and technologies of treatment of diseases of blood, and also lets out unique pharmacological production. However, access to the services of medical institutions is very difficult, as such promotion of services of the Institute is not actually made.

\subsection{Features of positioning of breakthrough companies.}

Breakthrough medical organizations have unique scientific and medical abilities and provide fundamentally different from other medical institutions services that have no analogues not only in St. Petersburg or the North-West region, but also in Russia as a whole, and sometimes in the world. [14] This type of institutions, as a rule, has a fairly high level of funding, both due to the unique products available in their Arsenal, and due to the recognition of the brand and the targeted allocation of funds from both different stakeholders and the state. $[15,16]$ 
Such medical organizations use effective promotion tools and focus on a sufficiently wealthy and highly in need of their services target audience. They are able to justify to the state and stakeholders their unique abilities and socio-economic significance of their activities in order to obtain sufficient budget funding and provide their technical base. [10, 17]

As a successful example of a breakthrough medical institution can lead sports Clinic Igor Kuznetsov, specializing in surgical (arthroscopic) treatment of injuries and joint pathology, as well as rehabilitation after injuries and surgical treatment. Igor Kuznetsov created the clinic using his own (personal) brand. Being a Professor of RNIITO. R. R. Vredena and one of the founders of arthroscopic surgical direction in Russia, Ia Kuznetsov focused the clinic on the target audience of athletes for whom joint injuries are the most common and dangerous in terms of future sports career. The clinic accepts all patients with similar pathologies and injuries, but the main emphasis in its activities is on sports medicine. For a long time the activity of the clinic in St. Petersburg was absolutely unique. Currently, such operations are done by many medical institutions, but the use of the most advanced materials and tools, unique practical experience and techniques allow the clinic to more accurately diagnose and demonstrate more effective and rapid results of rehabilitation after surgery, which leads to high customer loyalty.

\section{Discussion}

It should be noted that due to the implementation of the breakthrough concept of strategic development, the medical institution is able to attract more than average profits for the entire range of services and complementary products. The consumer is willing to pay more for the additional value, which in his eyes have the services of the medical institution. The consumer trusts this medical institution, he demonstrates his loyalty and, sharing his impressions about the results of treatment, actually acts as a part-time marketer. However, the application of this concept raises a number of problems.

The problem of assessing the quality of medical services. Consumers are more likely to pay attention to the perceived qualities of a medical service based on its perceived consumer characteristics and the prestige of the medical institution providing them. [18] These indicators may not correlate at all with real indicators of quality and efficiency of medical services, there is an effect of "independence of treatment prescription from potential results".[19] in the research of medical companies (as opposed to Universities, museums and other social organizations) there is a big error: the research conducted by the authors and the Department of economic theory and economic policy of St. Petersburg state University in 2007-2016. it was shown that the assessment of competitive positions of medical companies in about $22-28 \%$ of cases is distorted due to incorrect assessment of the quality of medical services. [20]

The problem of positioning and homogeneity of patients. There are large differences in the provision of medical services to patients first encountered by medical institutions and patients-professionals, these differences relate to the "basic" state of health of patients, according to Matthew C. Harris and Jennifer L. Kohn. [21] unfortunately, these differences are almost not taken into account in positioning and, therefore, do not affect the strategy of increasing competitiveness. The situation is compounded by problems in establishing criteria for treatment. [22] moreover, often the availability of treatment does not depend on the need and capacity of the health system, but on whether the relevant medical procedures fall into the appropriate social program (which depends, for example, on the maximization of empirical well-being by politicians (EWM) [23]). Consequently, the competitiveness of health-care providers and, consequently, the incentives of health-care providers may depend on completely non-market components (from purely political reasons to improving patient education). [24, 25] 
Studies of these issues will allow us to refine the model and offer a more adequate mathematical apparatus for obtaining the final results.

\section{Conclusion}

These examples confirm the effectiveness of breakthrough positioning of medical institutions and prove the high contribution of an effective competitive strategy in the market of medical services to the revenue component of the medical institution. It should be noted that effective positioning allows to achieve outstanding results and ensure high competitiveness of the region, which determines both the use of non-standard methods of business organization and specific state support. The studies conducted by the authors also confirm the impact of effective positioning of the medical institution in ensuring the quality of life of the population of the region in which the advanced medical institution operates. For the medical institution itself, the choice of the right positioning dominants contributes to the development of a strong brand, priority choice, the ability to become a member of a high-budget medical program, as well as a high level of trust and loyalty of the consumer.

\section{References}

1. I.A. Blagikh. Theoretical and methodological approaches to the substantiation of the economic policy of modern Russia. Political Economy Issues, 2, 67-75. (2016)

2. Yu.Vertakova et al. The formation of points of cluster growth of economic development of the territory. OrelSIET Bulletin, 2, 56-61. (2015)

3. Zh. A. Aliaskarova. Import substitution in terms of sanctions and counter-sanctions: successes, problems and prospects. Marketing MBA. Marketing management firms, 9 (4), 5-17. (2018)

4. Yu.Vertakova, V.Plotnikov Russian and foreign experience of interaction between government and business. World Applied Sciences Journal, 28, 411-415. (2013)

5. A.A. Kirillovskaya, et al. The Newest economic policy, government regulation of the economy and economic security. Globalization and its Socio-Economic Consequences. 16th International Scientific Conference Proceedings. Zilina, Rajecke Teplice, Slovak Republic, 870-875. (2016)

6. P. Segerstrom. Innovation, imitation, and economic growth. Journal of Political Economy, 99(4), 807-827. (1991)

7. Yu.G. Herzik Formation of cluster systems in the field of healthcare and the medical industry. Economics and Management: Problems, Solutions, 4 (5-2), 23-27. 2017

8. T.S. Krasnikova. Analytical review of approaches to defining the concept of "cluster" and assessing the role of clusters in the development of the territory. Marketing MBA. Marketing management firms, 7 (1), 144-157. (2016)

9. Porter M.E. Clusters and the New Economics of Competition. Harvard Business Review, 76 (6), 77-90. (1998)

10. N. A. Paskus et al. Strategic marketing: tutorial and workshop for undergraduate and graduate. Urait: Moscow. (2016).

11. A.V. Gubin et al. Regional medical cluster: organization and development prospects. Spatial economics, 3, 167-179. (2017)

12. J. Cagan, C.M. Vogel. Creating breakthrough products. innovation from product planning to program approval. FT Press, Upper Saddle River, New Jersey. (2001) 
13. E. Kamenica. Information economics. Journal of Political Economy, 125 (6), 18851890 (2017)

14. A.A.Lin, A.S.Ivanov. Competitive advantages of innovative pharmaceutical clusters (on the example of the St. Petersburg pharmaceutical cluster). Scientific reports of Belgorod State University. Series: Medicine. Pharmacy. 5, 149-157. (2017)

15. K.L.Keller. Economic and behavioral perspectives on brand extension. Marketing Science, 31, 772-775 (2012)

16. A.V.Volkova, T.A. Kulakova, Zh.A.Aliaskarova. «Smart regulation» and models of civil cooperation in the context of global challenges. Globalization and its SocioEconomic Consequences. 17th International Scientific Conference Proceedings. Rajecke Teplice, Slovakia, 2903-2910. (2017)

17. A.V. Volkova. Classical technologies in public interaction within modern Russia. Historical, Philosophical, Political and Law Sciences, Culturology and Study of Art. Issues of Theory and Practice, 5-2, 39-43. (2012)

18. V. Pashkus, N. Pashkus, A. Chemlyakova. Model for assessment of healthcare institutions' competitiveness. CBU International Conference Proceedings 2017. Prague, Czech Republic, 361-365. (2017)

19. M.A. Masten, A. Poirier. Identification of treatment effects under conditional partial independence. Econometrica, 86 (1), 317-351. (2018)

20. V. Pashkus, N. Pashkus, A. Chemlyakova. The problem of quality correlation and efficiency of medical services as a factor of health organizations competitiveness. $C B U$ International Conference Proceedings 2017. Prague, Czech Republic, 366-370. (2017).

21. M.C. Harris, J.L. Kohn. Reference health and the demand for medical care. The Economic Journal, 128 (615), 2812-2842. (2018)

22. S. Lee, B. Salanié. Identifying effects of multivalued treatments. Econometrica, 86 (5), 1939-1963. (2018)

23. T. Kitagawa, A. Tetenov. Who should be treated? empirical welfare maximization methods for treatment choice. Econometrica, 86 (2), 591-616. (2018)

24. L. Einav, A.Finkelstein, N. Mahoney provider incentives and healthcare costs: evidence from long-term care hospitals. Econometrica, 86 (6), 2161-2219 (2018)

25. J.J. Heckman, J. E.Humphries, G.Veramendi. Returns to education: The causal effects of education on earnings, health, and smoking. Journal of Political Economy,126, (S1), S197-S246. (2016) 